Journal of Management and Bussines (JOMB)

Volume 1, Nomor 2, Desember 2019

p-ISSN : 2656-8918

e-ISSN:2684-8317

DOI : https://doi.org/10.31539/jomb.v1i2.636

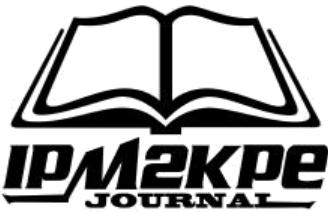

\title{
ANALISIS KETERLIBATAN FASHION DAN GAYA HIDUP BERBELANJA TERHADAP PEMBELIAN IMPULSIF PADA DISTRO PLATT MARS CABANG KOTA SUKABUMI
}

\author{
Rayyisa Nurul Haq ${ }^{1}$, Acep Samsudin ${ }^{2}$, Faizal Mulia $Z^{3}$ \\ Univesitas Muhammadiyah Sukabumi ${ }^{1,2,3}$ \\ rayyisanurulhaq@gmail.com ${ }^{1}$
}

\begin{abstract}
ABSTRAK
Tujuan penelitian ini adalah untuk menganalisis pengaruh keterlibatan fashion dan gaya hidupterhadap pembelian impulsif distro platt mars. Metode dalam penelitian ini menggunakan jenis sampel probability sampling termasuk kedalam simple random sampling. Teknik analisis yang digunakan adalah uji validitas, uji reliabilitas, analisis regresi linear berganda termasuk uji koefisien determinasi, koefisien korelasi ganda, dan pengujian hipotesis menggunakan uji secara stimultan (uji F). Hasil penelitian uji koefisien determinasi dilihat dari nilai (Adjusted $\mathrm{R}^{2}$ ) sebesar 0,325 dapat diartikan bahwa pengaruh Keterlibatan Fashion dan Gaya Hidup Berbelanja terhadap Pembelian Impulsif adalah sebesar 32,5\%. Sisanya 67,5\% dipengaruhi oleh faktor-faktor lain diluar penelitian ini. Berdasarkan uji koefisien korelasi ganda dilihat dari nilai R sebesar 0,582 menunjukan bahwa terjadi hubungan yang kuat antara keterlibatan fashion dan gaya hidup berbelanja dengan pembelian impulsif. Berdasarkan uji $\mathrm{F}$ nilai probabilitas sig. $0,000<0,05$. Simpulan, secara bersama-sama Keterlibatan Fashion $\left(\mathrm{X}_{1}\right)$ dan Gaya Hidup Berbelanja $\left(\mathrm{X}_{2}\right)$ berpengaruh secara signifikan terhadap Pembelian Impulsif (Y).
\end{abstract}

Kata Kunci: Keterlibatan Fashion, Gaya Hidup Berbelanja, Pembelian Impulsif

\section{ABSTRACT}

The purpose of this study was to analyze the effect of fashion and lifestyle involvement on impulsive purchases of distro platt mars. The method in this study uses a type of probability sampling, including simple random sampling. The analysis technique used is the validity test, reliability test, multiple linear regression analysis including the coefficient of determination test, multiple correlation coefficients, and testing the hypothesis using the test simultaneously ( $F$ test). The results of the test of the coefficient of determination seen from the value (Adjusted R2) of 0.325 can be interpreted that the influence of Fashion Involvement and Shopping Lifestyle on Impulsive Purchases is $32.5 \%$. The remaining $67.5 \%$ is influenced by other factors outside this study. Based on the multiple correlation coefficient test seen from the $R$ value of 0.582 shows that there is a strong relationship between fashion involvement and shopping lifestyle with impulsive purchases. Based on the F test the probability value sig. 0,000 <0.05. Conclusions, together with Fashion Involvement (X1) and Shopping Lifestyle (X2) significantly influence Impulsive Purchase (Y).

Keywords: Fashion Involvement, Shopping Lifestyle, Impulsive Purchasing 


\section{PENDAHULUAN}

Bisnis fashion yang ada di kota Sukabumi terbilang cukup banyak, dan sangat berkembang pesat diikuti dengan zaman yang semakin modern. Bisa dilihat dengan adanya Distro dan Outlet yang menjual produk fashion dengan gaya dan model yang berbeda. Perkembangan fashion menjadikan seseorang memerhatikan gaya hidupnya, karena gaya hidup sangat erta hubungannya dengan fashion. Tidak bisa dipungkiri bahwa dari tahun ke tahun fashion selalu mengalami kemajuan yang cukup bagus dan manusia tidak bisa terlepas dari industri fashion. Salah satu industri fashion yang yang perkembangannya sangat cepat adalah pakaian, karena pakaian lebih banyak di minati masyarakat dan selalu mengikuti mode dan trend terkini untuk tampil trendy dan stylish. (Utami dalam Rahmawati, 2016).

Maka dari itu setiap perusahaan dituntut untuk lebih inovatif dan kreatif dalam menciptakan pakaian yang dapat menjadi trend fashion yang banyak diminati konsumen, dengan model yang fashionable. Mengembangkan kualitas produk yang di pasarkan juga penting karena untuk menembus pasar yang luas semakin ketat, dengan banyaknya bisnis fashion yang tidak hanya dari dalam negeri saja maka baiknya setiap usaha fashion harus memberikan fasilitas, pelayanan, kepuasan kepada konsumen dengan memberikan tempat yang nyaman dan promo seperti adanya discount, sale dan event. Perusahaan juga harus lebih memperhatikan tampilan toko agar terlihat lebih menarik yang nantinya bisa merangsangadanya pembelian impulsif, hal ini tentunya akan meningkatkan penjualan dan menguntungkan bagi perusahaan.

Pembelian impulsif merupakan pembelian secara tiba-tiba atau tidak direncanakan sebelumnya, terjadi begitu saja ketika seseorang melihat suatu produk atau membeli sebuah produk secara spontan (Ma'aruf, 2006). Pembelian impulsif tidak didasari oleh niat sebelumnya, tetapi didasari oleh dorongan emosi dalam diri seseorang, emosi positif ini akan meningkat ketika faktor lingkungan yang mendukung dan tampilan visual toko yang menarik perhatian yang membuat seseorang ingin mengunjungi toko tersebut.

Keterlibatan fashion adalah ketertarikan seseorang dalam sebuah produk fashion, adanya daya tarik yang terus menerus dari suatu produk dan keterlibatan suatu produk yang tinggi sehingga munculnya ketertarikan untuk membeli produk tersebut, dan daya tarik emosional sehinga menarik konsumen untuk membeli suatu produk. 
(Setiadi, 2010). Adanya keterlibatan konsumen dalam produk fashion karena kebutuhan dan nilai dari produk tersebut yang sangat berhubungan dengan sifat konsumen karena pengetahuannya mengenai fashion yang juga berhubungan dengan gaya hidup konsumen, up-to-date fashion yang membuat konsumen ingin membeli produk terbaru karena modelnya unik dan terkini.

Seseorang yang mengikuti trend fashion dan perkembangan zaman akan mempengaruhi gaya hidupnya dalam berbelanja karena adanya ketertarikan dalam produk fashion, sehingga memicu minat konsumen untuk berbelanja. Biasanya karakteristik konsumen ini berpacu pada bagaimana menghabiskan waktu dan uang mereka. Keterlibatan produk fashion di dukung dengan adanya gaya hidup berbelanja yang semakin meningkat karena setiap orang pasti lebih memikirkan cara dan bagaimana berpenampilan dengan baik.

Gaya hidup berbelanja adalah bagaimana seseorang mengekspresikan tentang lifestyle dalam berbelanja yang mencerminkan perbedaan status sosial. Cara kita berbelanja mencerminkan status sosial seseotang ketika berbelanja, martabat, dan kebiasaan seseorang dengan gaya hidupnya yang selalu mengehabiskan uang dengan berbelanja (Setiadi, 2010). Gaya hidup mengalami perkembangan yang menjadikan seseorang mengikuti perkembangannya, hal ini yang menjadikan seseorang hobby untuk berbelanja. Memperhatikan setiap merek ataupun ada tawaran khusus yang diberikan perusahaan menjadi seseorang ingin membeli produk tersebut.

Tema yang diusulkan peneliti adalah Analisis Keterlibatan Fashion Dan Gaya Hidup Berbelanja Terhadap Pembelian Impulsif Pada Distro Platt Mars. Tujuan penelitian ini yaitu untuk mengetahui bagaimana pengaruh keterlibatan fashion dan gaya hidup berbelanja terhadap pembelian impulsif pada distro platt mars.

\section{KAJIAN TEORI}

\section{Keterlibatan Fashion}

Keterlibatan (Involvement) adanya hubungan seseorang pada sebuah produk karena ketertarikan, kebutuhan pada produk tersebut. (Zaichkowsky dalam Japarianto \& Sugiharto, 2011). Dalam pemasaran fashion, keterlibatan fashion merupakan ketertarikan seseorang terhadap produk fashion yaitu baju, sepatu, tas (Kim dalam Sembiring, 2013). 
Selain itu keterlibatan fashionberhubungan erat dengan karakteristik pribadi terutama kaum muda karena pengetahuannya mengenai fashion (O'Cass dalam Arnika 2017). Menurut Park et al, (2006) untuk mengukur keterlibatan fashion menggunakan karakteristik sebagai berikut:

1. Up to date Fashion, memiliki satu atau lebih pakaian dengan gaya terbaru.

2. Dressing Smartly, bagian penting dari hidup dan kegiatan saya adalah berpakaian rapi.

3. Shopping Fashion Speciality Stores, saya memilih berbelanja di butik atau toko khusus mode, bukan di department store.

4. Dress for Fashion Not Comfort, berpakaian karena fashion, buka karena nyaman.

\section{Gaya Hidup Berbelanja}

Gaya hidup berbelanja merupakan ekspresi dalam lifestyle dalam berbelanja yang mencerminkan perbedaan status sosial, kebiasaan dan martabat seseorang (Betty Jackson dalam Sembiring, 2013). Selain itu juga gaya hidup berbelanja merupakan gaya hidup konsumen pada kategori fashion yang menunjukan sikapnya terhadaap merk tertentu, pengaruh iklan dan kepribabadian (Prastia dalam Setiawan 2015).

Menurut Cobb dan Hoyer dalam Rahmawati (2018) mengemukakan bahwa indikator gaya hidup berbelanja adalah sebagai berikut:

1. Menanggapi untuk setiap iklan mengenai suatu produk

2. Membeli pakaian model terbaru

3. Berbelanja merk yang paling terkenal

4. Yakin bahwa merk terkenal yang dibeli terbaik dalah hal kualitas

5. Sering membeli berbagai merk

\section{Pembelian Impulsif}

Pembelian impulsif merupakan pembelian yang tidak direncanakan sebelumnya, ini terjadi secara tiba-tiba, spontan dan lebih kepada rasa emosional seseorang ketika melihat barang atau produk (Park dalam Rahmawati, 2018). Menurut Utami dalam fakhtul, suharyono, \& yulianto (2016) "Pembelian impulsif adalah pembelian yang terjadi ketika konsumen melihat produk atau merek tertentu, kemudian konsumen 
menjadi tertarik untuk mendapatkannya, biasanya karena adanya ransangan yang menarik dari toko tersebut".

Menurut Bayley dan Nancarrow dalam manggiasih (2012) mengelompokkan pembelian impulsif menjadi empat indikator:

1. Pembelian spontan, merupakan keadaan dimana pelanggan seringkali membeli sesuatu tanpa direncanakan terlebih dahulu, hal tersebut biasanya disebabkan oleh respon konsumen ketika berada di dalam toko.

2. Pembelian tanpa berpikir akibat, merupakan keadaan dimana pelanggan sering melakukan pembelian tanpa memikirkan terlebih dahulu mengenai akibat dari pembelian yang dilakukan.

3. Pembelian terburu-buru, merupakan keadaan dimana pelanggan seringkali merasa bahwa terlalu terburu-buru dalam membeli sesuatu.

4. Pembelian dipengaruhi keadaan emosional, adalah penilaian pelanggan dimana pelanggan melakukan kegiatan berbelanja dipengaruhi oleh keadaan emosional yang dirasakan.

Serta hubungan keterlibatan fashion (X1) dan gaya hidup berbelanja (X2) terhadap pembelian impulsif (Y). Ristiana (2016) mendapatkan hasil yang positif bahwa keterlibatan fashion dan gaya hidup berbelanja yang dirasakan merupakan anteseden yang cukup siginifikan terhadap pembelian impulsif dalam industri fashion. Keterlibatan fashion dan gaya hidup berbelanja mempunyai peranan yang sangat mempengaruhi pembelian impulsif.

\section{METODE PENELITIAN}

Penelitian ini dilaksanakan di CV. Platt Mars (Distro Platt Mars) Kota Sukabumi. Menggunakan pendekatan manajemen pemasaran, yang khususnya membahas tentang Keterlibatan Fashion, Gaya Hidup Berbelanja dan Pembelian Impulsif. Dalam penelitian ini terdapat tiga variabel yang dijadikan kawasan penelitian yaitu Keterlibatan Fashion (Variabel X1), gaya hidup berbelanja (Variabel X2), dan juga Pembelian Impulsif (Variabel Y). dalam penelitian ini yang dijadikan variabel terikat (dependent variable) yaitu pembelian impulsif, dan yang dijadikan variabel bebas (independent variable) yaitu keterlibatan fashion dan gaya hidup berbelanja. 
Penelitian yang dijadikan variabel bebas (independent variable) adalah keterlibatan fashion dan gaya hidup berbelanja. Keterlibatan fashion terdiri dari empat dimensi, yaitu: up to date fashion, dressing smartly, shopping fashion speciality stores, dress for fashion not comfort.

Sedangkan gaya hidup berbelanja terdiri dari lima dimensi, yaitu: menanggapi untuk setiap iklan mengenai suatu produk, membeli pakaian model terbaru, berbelanja merk yang paling terkenal, yakin bahwa merk terkenal yang dibeli terbaik dalah hal kualitas, sering membeli berbagai merk. Dan yang menjadi variabel terikat (dependent variable) adalah pembelian impulsif yang meliputi empat dimensi, yaitu : pembelian spontan, merupakan keadaan dimana pelanggan seringkali membeli sesuatu tanpa direncanakan terlebih dahulu, hal tersebut biasanya disebabkan oleh respon konsumen ketika berada di dalam toko, pembelian tanpa berpikir akibat, merupakan keadaan dimana pelanggan sering melakukan pembelian tanpa memikirkan terlebih dahulu mengenai akibat dari pembelian yang dilakukan, pembelian terburu-buru, merupakan keadaan dimana pelanggan seringkali merasa bahwa terlalu terburu-buru dalam membeli sesuatu, pembelian dipengaruhi keadaan emosional, adalah penilaian pelanggan dimana pelanggan melakukan kegiatan berbelanja dipengaruhi oleh keadaan emosional yang dirasakan.

Populasi dalam penelitian ini adalah konsumen yang pernah berkunjung ke CV. Platt Mars (Distro Platt Mars) Kota Sukabumi. Metode yang digunakan adalah menggunakan teknik probability sampling dengan metode pendekatan simple random sampling dan dengan melakukan penyebaran kuesioner sebanyak 100 kepada responden. Teknik analisis yang digunakan adalah uji validitas, uji reliabilitas, teknik analisis koefisien korelasi ganda, koefisien determinasi, regresi linear berganda dan pengujian hipotesis menggunakan uji secara simultan (uji F).

\section{HASIL PENELITIAN}

\section{Uji Validitas}

Uji validitas adalah suatu taraf di mana alat pengukur dapat mengukur apa yang seharusnya diukur sehingga suatu penelitian yang menggunakan kuesioner sebagian besar pengukurnya perlu diuji validitasnya. Biasanya syarat minimum untuk dianggap 
memenuhi syarat adalah kalau $r=0,3$. Jadi jika korelasi antara butir dengan skor total kurang dari 0,3 maka butir dengan instrumen dinyatkan tidak valid.

Berdasarkan pengujian validitas menggunakan bantuan software SPSS 24 diperoleh hasil sebagai berikut:

Tabel 1 Hasil Uji Validitas

\begin{tabular}{lcccc}
\hline \multicolumn{1}{c}{ Valid } & item & r-hitung & r-kritis & Ket \\
\hline \multirow{2}{*}{ Keterlibatan } & 1 & 0,629 & 0,3 & Valid \\
Fashion (X1) & 2 & 0,502 & 0,3 & Valid \\
& 3 & 0,478 & 0,3 & Valid \\
& 4 & 0,722 & 0,3 & Valid \\
\hline \multirow{2}{*}{ Gaya Hidup } & 5 & 0,670 & 0,3 & Valid \\
Berbelanja & 1 & 0,708 & 0,3 & Valid \\
(X2) & 3 & 0,750 & 0,3 & Valid \\
& 4 & 0,734 & 0,3 & Valid \\
\hline Pembelian & 5 & 0,475 & 0,3 & Valid \\
Impulsif (Y) & 1 & 0,603 & 0,3 & Valid \\
& 2 & 0,533 & 0,3 & Valid \\
& 3 & 0,439 & 0,3 & Valid \\
& 4 & 0,528 & 0,3 & Valid \\
& 5 & 0,506 & 0,3 & Valid \\
& 6 & 0,585 & 0,3 & Valid \\
& 7 & 0,491 & 0,3 & Valid \\
\hline
\end{tabular}

Sumber : Data Primer (Kuesioner), 2019

Berdasarkan data tabel diatas, dapat diketahui bahwa nilai korelasi antara skor item variabel Keterlibatan Fashion $\left(\mathrm{X}_{1}\right)$, Gaya Hidup Berbelanja $\left(\mathrm{X}_{2}\right)$ dan Pembelian Impulsif (Y) seluruh item pada hasil pengujian tersebut memiliki skor diatas 0,3 sehingga seluruh butir instrumen item Keterlibatan Fashion $\left(\mathrm{X}_{1}\right)$, Gaya Hidup Berbelanja $\left(\mathrm{X}_{2}\right)$ dan Pembelian Impulsif $(\mathrm{Y})$ dinyatakan valid.

\section{Uji Reliabilitas}

Tabel 2 Hasil Uji Reliabilitas

\begin{tabular}{lccc}
\hline \multirow{1}{*}{ Variabel } & \multicolumn{2}{c}{$\begin{array}{c}\text { Koefisien } \\
\text { Cronbach's Alpha }\end{array}$} & \multirow{2}{*}{ Ket } \\
\cline { 2 - 3 } & Hitung & Standar & \\
\hline $\begin{array}{l}\text { Keterlibatan } \\
\text { Fashion (X1) }\end{array}$ & 0,736 & 0,6 & Reliabel \\
\hline $\begin{array}{l}\text { Gaya Hidup } \\
\text { Berbelanja } \\
\text { (X2) }\end{array}$ & 0,764 & 0,6 & Reliabel \\
\hline $\begin{array}{l}\text { Pembelian } \\
\text { Impulsif(Y) }\end{array}$ & 0,694 & 0,6 & Reliabel \\
Sumber: Data Primer (Kuesioner), 2019 & \\
\hline
\end{tabular}


Dari tabel pengujian di atas diperoleh hasil yang menunjukkan $\alpha$ hitung $>\alpha$ standar $(0,6)$ sehingga dapat disimpulkan bahwa variabel-variabel yang dipakai dalam penelitian ini adalah reliabel. Dengan demikian maka jelaslah bahwa variabel-variabel tersebut dapat digunakan untuk penelitian selanjutnya karena dapat diandalkan.

\section{Koefisien Korelasi Ganda (R)}

Tabel 3 Hasil Koefisien Korelasi Ganda

\begin{tabular}{|c|c|c|c|c|}
\hline \multicolumn{5}{|c|}{ Model Summary } \\
\hline Model & $\mathrm{R}$ & $\begin{array}{c}\mathrm{R} \\
\text { Square }\end{array}$ & $\begin{array}{l}\text { Adjusted R } \\
\text { Square }\end{array}$ & Std. Error of the Estimate \\
\hline 1 & $.582^{\mathrm{a}}$ & .339 & .325 & 4.233 \\
\hline
\end{tabular}

Sumber : Data Primer (Kuesioner), 2019

Berdasarkan tabel 5 diatas diperoleh angka R sebesar 0,582 berada pada kategori 0,40-0,599. Hal ini menunjukan bahwa terjadinya hubungan yang keterlibatan fashiondan gaya hidup berbelanja dengan pembelian impulsif.

\section{Koefisien Determinasi $\left(\mathbf{R}^{2}\right)$}

Tabel 4 Hasil Koefisien Determinasi

\begin{tabular}{|c|c|c|c|c|}
\hline \multicolumn{5}{|c|}{ Model Summary } \\
\hline Model & $\mathrm{R}$ & R Square & $\begin{array}{l}\text { Adjusted R } \\
\text { Square }\end{array}$ & Std. Error of the Estimate \\
\hline 1 & $.582^{\mathrm{a}}$ & .339 & .325 & 4.233 \\
\hline
\end{tabular}

Sumber : Data Primer (Kuesioner),2019

Hasil tabel 4 diatas model summary menyatakan besarnya adjusted $\mathrm{R}^{2}$ sebesar 0,325; hal ini berarti 32,5\% variasi pembelian impulsif dapat dijelaskan oleh variasi dari dua variabel independen yaitu keterlibatan fashion dan gaya hidup berbelanja sedangkan sisanya $67,5 \%(100 \%-32,5 \%=67,5 \%)$ dari faktor yang tidak diteliti.

\section{Hasil Analisis Regresi Linear Berganda}

Regresi linear berganda digunakan untuk mengetahui seberapa besar pengaruh faktor yang digunakan dalam model penelitian keterlibatan fashion dan gaya hidup berbelanja terhadap pembelian impulsif. Hasil regresi linear berganda dapat dilihat pada tabel 1 sebagai berikut: 
Tabel 5 Hasil Uji Regresi Liniear Berganda

\begin{tabular}{|c|c|c|c|c|c|}
\hline \multicolumn{6}{|c|}{ Coefficients $^{\mathrm{a}}$} \\
\hline \multirow[b]{2}{*}{ Model } & Unstandardize & Coefficients & $\begin{array}{l}\text { Standardized } \\
\text { Coefficients }\end{array}$ & \multirow[b]{2}{*}{$\mathrm{t}$} & \multirow[b]{2}{*}{ Sig. } \\
\hline & $\mathrm{B}$ & Std. Error & Beta & & \\
\hline \multirow{3}{*}{$\begin{array}{l}\text { 1(Constant) } \\
\text { Keterlibatan Fashion } \\
\text { Gaya Hidup Berbelanja }\end{array}$} & 2,710 & 4,219 & & ,642 & .522 \\
\hline & .244 & , 176 & .115 & 1,385 & .169 \\
\hline & 1,073 & .158 & .562 & 6,786 & .000 \\
\hline
\end{tabular}

Sumber : Data Primer (Kuesioner), 2019

Dari output uji regresi linear berganda diatas, maka dapat diperoleh persamaan sebagai berikut ini:

$$
Y=2,710+0,244 X_{1}+1,073 X_{2}
$$

\section{Uji Signifikasi Secara Simultan (Uji F)}

Tabel 6 Hasil Uji F

\begin{tabular}{|c|c|c|c|c|c|}
\hline \multicolumn{6}{|c|}{ ANOVA $^{\mathrm{a}}$} \\
\hline Model & Sum of Squares & df & $\begin{array}{c}\text { Mean } \\
\text { Square }\end{array}$ & $\mathrm{F}$ & Sig. \\
\hline $\begin{array}{l}1 \\
\text { Regression }\end{array}$ & 892.072 & 2 & 446.036 & 24.888 & $.000^{\mathrm{b}}$ \\
\hline Residual & 1738.438 & 97 & 17.922 & & \\
\hline $\begin{array}{l}\text { Total } \\
\text { a. Dependen }\end{array}$ & $\begin{array}{r}2630.510 \\
\text { Variable: Pembelia }\end{array}$ & $\begin{array}{l}99 \\
99 \\
\text { apuls }\end{array}$ & & & \\
\hline
\end{tabular}

Sumber : Data Primer (Kuesioner),2019

Hasil tabel 5 di atas, hasil uji $\mathrm{F}$ hitung variabel $\mathrm{X}_{1}$ (keterlibatan fashion), $\mathrm{X}_{2}$ (gaya hidup berbelanja) dan Y (pembelian impulsif) adalah sebesar 24.888. maka dapat diperoleh nilai sig. $0,000<0,05$; nilai $F_{\text {hitung }} 24.888>F_{\text {tabel }}$ 2.36. Artinya bahwa keterlibatan fashion dan gaya hidup berbelanja berpengaruh signifikan terhadap kepuasan konsumen. 


\section{PEMBAHASAN}

\section{Hasil Analisis Regresi Bersama-Sama}

Berdasarkan pada hasil hitungan penelitian analisis regresi berganda. Nilai koefisien determinasi $\left(\mathrm{R}^{2}\right)$ diperoleh dari hasil keterlibatan fashion (X1) dan gaya hidup berbelanja (X2) mempengaruhi sebesar 32,5\% (0,325) terhadap Pembelian Impulsif (Y), sisanya $67,5 \%$ dipengaruhi oleh faktor-faktor lain diluar penelitian ini.Hal ini dikarenakan penting nya keterkibatan fashion dan gaya hidup berbelanja berperan penting dalam meningkatkan Pembelian Impulsif. Dengan demikian dapat diketahui bahwa keterlibatan fashion (X1) dan gaya hidup berbelanja (X2) merupakan faktor yang membentuk pembelian impulsif (Y) pada Distro Platt Mars Cabang Sukabumi secara simultan.

Berdasarkan pada hasil hitungan penelitian analisis regresi berganda uji $\mathrm{F}$ dengan tingkat signifikan sebesar 0,1 (10\%) menunjukan bahwa variabel keterlibatan fashion $\left(\mathrm{X}_{1}\right)$ dan gaya hidup berbelanja $\left(\mathrm{X}_{2}\right)$ berpengaruh secara bersama-sama terhadap pembelian impulsif (Y). Hal ini ditunjukan dengan hasil nilai sig. $0,000<0,05$; nilai $F_{\text {hitung }}$ 24.888> $F_{\text {tabel }}$ 2.36. Nilai koefisien determinasi $\left(R^{2}\right)$ diperoleh hasil dari variabel keterlibatan fashion $\left(\mathrm{X}_{1}\right)$ dan gaya hidup berbelanja $\left(\mathrm{X}_{2}\right)$ mempengaruhi sebesar $32,5 \%$ $(0,325)$ terhadap pembelian impulsif $(Y)$, sisanya $67,5 \%$ dipengaruhi oleh faktor-faktor lain diluar penelitian ini. Hal ini dikarenakan suatu keterlibatan fashion dan gaya hidup berbelanja berperan penting dalam memberikan suatu kepuasan kepada konsumen. Dengan demikian dapat diketahui bahwa keterlibatan fashion $\left(\mathrm{X}_{1}\right)$ dan gaya hidup berbelanja $\left(\mathrm{X}_{2}\right)$ merupakan faktor yang membentuk pembelian impulsif (Y) Pada Disto Platt Mars Cabang Sukabumi secara simultan.

\section{SIMPULAN}

Penelitian ini bertujuan untuk menganalisis pengaruh keterlibatan fashion dan gaya hidup berbelanja terhadap pembelian impulsif. Berdasarkan dari hasil analisis yang telah dilakukan, maka dapat disimpulkan bahwa dari hipotesis menunjukan keterlibatan fashion dan gaya hidup berbelanja berpengaruh terhadap pembelian impulsif. Dan dengan keterlibatan fashion semakin tinggi, semkin memicunya pembelian impulsif dan gaya hidup berbelanja yang semakin mingkat angkat meningkatkan pembelian impulsif seseorang juga. Hasil analisis dalam penelitian ini menunjukan bahwa keterlibatan fashion dan gaya hidup berbelanja berpengaruh terhadap pembelian impulsif. 


\section{DAFTAR PUSTAKA}

Arnika, A. S. (2017). Pengaruh Shopping Lifestyle, Discount, Fashion Involvement, dan Promosi Penjualan Terhadap Impulse Buying: Fakultas Ilmu Sosial dan Ilmu Politik Universitas Lampung. (Skripsi)

Ristiana, E. (2016). Pengaruh Gaya Hidup Berbelanja dan Ketertarikan Fashion terhadap Perilaku Pembelian Impulsif Pakaian Distribution Store (Distro) di Yogyakarta: Fakultas Ekonomi Universitas Negeri Yogyakarta (Skripsi)

Fatkhul M., Suharyono, S., Yulianto, E. (2016). Analisis Faktor-Faktor Yang Berpengaruh terhadap Pembelian Impulsif di Distro 3second Cabang Mall Olympic Garden Malang : Fakultas Ilmu Administrasi Universitas Brawijaya Malang. Jurnal Administrasi Bisnis, 36(1), 92-100

Japariyanto, J., Sugiono, S. (2011). Pengaruh Shopping Lifestyle dan Fashion Involvement terhadap Impulse Buying Behavior Masyarakat High Income Surabaya. Skripsi: Fakultas Ekonomi Universitas Keristen Petra

Ma'ruf, H. (2006). Pemasaran Ritel. Jakarta: PT Gramedia Pustaka Utama

Manggiasih F P., Widiartono, W., Prabawani, B. (2012). Pengaruh Discount, Merchandising dan Hedinic Shopping Motives Terhadap Impulse Buying: Fakultas Ekonomi Universitas Islam Sultan Agung, 13

Park E. J., Kim, E. Y., Forney, J. C. (2006). A Structural Model of Fashion Oriented Impulse Buying Behavior. Journal of Fashion Marketing and Management, 10(4). DOI: $10.1108 / 13612020610701965$

Rahmawati N, T. (2018). Pengaruh Hedonic Shopping Value dan Shopping Lifestyle terhadap Impulse Buying dengan Emosi Positif sebagai Variabel Mediasi: Skripsi: Jurusan Manajemen Fakultas Ekonomi Universitas Negeri Yogyakarta.

Sembiring, S. (2013). Pengaruh Shopping Lifestyle dan Fashion Involvement terhadap Impulse Buying Behaviour.Bandung:Jurusan Manajemen, Fakultas Ekonomi, Universitas Komputer Indonesia

Setiadi, N. J. (2010). Perilaku Konsumen: Perspektif Kontemporer pada Motif, Tujuan dan Keinginan Konsumen. Jakarta: Kencana

Setiawan, S., Dewangga, R. (2015). Pengaruh Shopping Lifestyle, Fashion Involvement dan Hedonic Shopping Value Terhdap Impulsive Buying Behaviour: Fakultas Ekonomi UAJY 